\title{
Internacionalização da Educação Superior: redefinições, justificativas e estratégias
}

\section{Internationalization of Higher Education: redefinitions, justifications and strategies}

\section{Internacionalización de la Educación Superior: redefiniciones, justificativas y estrategias}

\author{
José Camilo dos Santos Filho ${ }^{1}$
}

DOI: http://dx.doi.org/10.20435/serie-estudos.v0i0.1383

\begin{abstract}
Resumo: Neste texto de cunho teórico, tratamos de três aspectos que consideramos relevantes para a compreensão do tema da internacionalização da Educação Superior: (1) conceitos de internacionalização da Educação Superior, destacando as diferentes perspectivas de sua definição; (2) razões ou rationales da internacionalização da Educação Superior, sintetizadas em duas grandes categorias por alguns autores - razões políticas e econômicas e razões culturais e educacionais - ou em quatro por outros autores - razões política, econômica, sociocultural e acadêmica; e (3) estratégias de internacionalização da Educação Superior, traduzidas num conjunto de atividades que operacionalizam a política da instituição universitária. A implementação da política de internacionalização implica comprometimento efetivo, seja no nível estatal, seja no nível institucional, com sua incorporação explícita nos propósitos e funções atuais da universidade contemporânea.
\end{abstract}

Palavras-chave: internacionalização e Educação Superior; internacionalização da Educação Superior; conceitos de internacionalização; razões da internacionalização; estratégias de internacionalização.

\begin{abstract}
The purpose of this theoretical paper is to analyze the issue of Higher Education internationalization in three relevant aspects: definitions, rationales and strategies. The definitions of Higher Education internationalization are approached from different perspectives. The rationales of Higher Education internationalization are synthesized by some authors in two broad categories - political/economical and cultural/educational reasons - and by others in four categories political, economic, sociocultural and academic reasons. The strategies for Higher Education internationalization are translated into a set of strategies and activities that operationalize the politics of the university institution. The implementation of internationalization policy implies effective commitment at the state level, and at the institutional level, with its explicit incorporation into the current purposes and functions of contemporary university.
\end{abstract}

\footnotetext{
${ }^{1}$ Universidade Estadual de Campinas (UNICAMP), Campinas, São Paulo, Brasil.
} 
Keywords: internationalization and Higher Education; Higher Education internationalization; concepts of internationalization; reasons for internationalization; internationalization strategies.

Resumen: En este texto de cuño teórico tratamos de tres aspectos que consideramos relevantes para la comprensión del tema de la internacionalización de la Educación Superior: (1) conceptos de internacionalización de la Educación Superior, señalando las distintas perspectivas de su definición; (2) razones o rationales de la internacionalización de la Educación Superior, sintetizadas en dos grandes categorías por algunos autores - razones políticas y económicas y razones culturales y educacionales - o en cuatro por otros autores - razones políticas, económicas, socioculturales y académicas; y (3) estrategias de internacionalización de la Educación Superior, traducidas en un conjunto de actividades que operacionalizan la política de la institución universitaria. La implementación de la política de internacionalización implica el comprometimiento efectivo, sea en nivel estatal, sea en nivel institucional, con su incorporación explícita en los propósitos y funciones actuales de la universidad contemporánea.

Palabras clave: internacionalización y Educación Superior; internacionalización de la Educación Superior; conceptos de internacionalización; estrategias de internacionalización.

\section{INTRODUÇÃO}

As primeiras universidades europeias surgiram no século XII já internacionalizadas tanto no corpo docente como no discente. Seu ambiente cosmopolita foi dominante até o surgimento dos estados nacionais modernos, que passaram a criar suas universidades nacionais. Na era moderna, apenas algumas poucas universidades dos países mais avançados, mais frequentemente em razão de laços coloniais, passaram a receber estudantes de suas colônias e/ou de países menos desenvolvidos cientificamente, como foi o caso da China, do Japão e dos Estados Unidos, que na segunda metade do século XIX enviaram milhares de jovens para estudar na Europa, especialmente na França, na Inglaterra e na Alemanha. Em grande medida, foi essa geração que, no retorno a seus países de origem, revolucionou as universidades.

Neste texto, trataremos de três aspectos que consideramos relevantes para a compreensão do tema da internacionalização da Educação Superior: (1) Conceitos e redefinições de internacionalização da Educação Superior; (2) Razões ou rationales da internacionalização da Educação Superior; e (3) Estratégias de internacionalização da Educação Superior. 


\section{CONCEITOS DE INTERNACIONALIZAÇÃO DA EDUCAÇÃO SUPERIOR}

Há uma variedade de termos relacionados à palavra internacionalização da Educação Superior, o que tem criado certa dificuldade para um entendimento consensual desse termo. Hans de Wit (2002) cita termos mais genéricos, mais específicos e concretos, bem como termos relacionados ao currículo. Entre os primeiros, elenca: educação internacional, estudos internacionais, internacionalismo, educação transnacional e globalização da Educação Superior. Entre os segundos: mobilidade acadêmica, cooperação internacional, estudos no exterior e intercâmbio internacional. Entre os terceiros: educação multicultural, educação intercultural, educação transcultural, educação para o entendimento internacional, educação para a paz, educação global, estudos transnacionais, estudos globais.

Delgado-Márquez, Hurtado-Torres e Bondar (2011) elaboraram uma classificação das definições de internacionalização da Educação Superior propostas por especialistas, segundo quatro perspectivas genéricas estabelecidas por Knight (1997): atividade, competição, éthos e processo. Essas perspectivas estão sintetizadas no Quadro 1.

Concebida na perspectiva da atividade, a internacionalização da Educação Superior é definida por Harari (1992), Klasek (1992) e Mestenhauser e Ellingboe (1998) como o processo de integração da educação internacional no currículo. Centrado nas atividades, este enfoque busca aumentar a cooperação internacional para assegurar aos países maior segurança nacional e melhor competitividade econômica (POWELL, 2004). 
Quadro 1 - Perspectivas de internacionalização no contexto das Instituições de Educação Superior

\begin{tabular}{|c|c|}
\hline 1. Perspectiva da atividade & Autores \\
\hline $\begin{array}{l}\text { Focaliza as atividades de Educação Superior } \\
\text { que fomentam uma dimensão intercultural, } \\
\text { incluída a presença do alunado internacional, } \\
\text { currículo e intercâmbio alunado/professorado. }\end{array}$ & $\begin{array}{l}\text { Harari (1992); Klasek (1992); Arum e } \\
\text { Van de Water (1992); Mestenhauser } \\
\text { e Ellingboe (1998); Green e Olson } \\
\text { (2003); Javalgi, Griffith e White } \\
\text { (2003); Powell (2004); Green e } \\
\text { Shoenberg (2006). }\end{array}$ \\
\hline 2. Perspectiva da competição & Autores \\
\hline $\begin{array}{l}\text { Destaca o desenvolvimento de habilidades, } \\
\text { de conhecimentos e de valores que são } \\
\text { importantes para que se possa competir no } \\
\text { mercado global. }\end{array}$ & $\begin{array}{l}\text { Soderqvist (2002); Van der Wende } \\
\text { (2007); Ayoubi e Massoud (2007); } \\
\text { McGowan e Potter (2008); Elkin, } \\
\text { Farmsworth e Templer (2008); Lipsett } \\
\text { (2009). }\end{array}$ \\
\hline 3. Perspectiva do éthos & Autores \\
\hline $\begin{array}{l}\text { Destaca a criação de uma cultura ou entorno } \\
\text { onde se valorizam e se apoiam as perspectivas } \\
\text { e as iniciativas interculturais/internacionais. }\end{array}$ & $\begin{array}{l}\text { Pickert e Turlington (1992); Hanson e } \\
\text { Meyerson (1995). }\end{array}$ \\
\hline 4. Perspectiva do processo & Autores \\
\hline $\begin{array}{l}\text { Enfatiza a integração de uma dimensão } \\
\text { internacional e intercultural no ensino, } \\
\text { na pesquisa e nos serviços, por meio de } \\
\text { uma combinação de atividades, políticas e } \\
\text { procedimentos. }\end{array}$ & $\begin{array}{l}\text { Knight (1994); Schoorinan (1999); De } \\
\text { Wit (2002); Olson et al. (2001). }\end{array}$ \\
\hline
\end{tabular}

Fonte: Delgado-Márquez, Hurtado-Torres e Bondar (2011).

Na perspectiva da competição, a internacionalização da Educação Superior é definida por Soderqvist (2002, p. 29) como

[...] o processo de transformação de uma instituição de educação superior nacional numa instituição de educação superior internacional, durante o qual se introduz uma dimensão internacional em todos os aspectos de sua gestão holística com o duplo objetivo de melhorar a qualidade do ensino e da aprendizagem e adquirir as competências desejadas.

O objetivo básico da internacionalização das universidades é captar estudantes estrangeiros, estudantes nacionais mais qualificados e pesquisadores de alto nível (VAN DER WENDE, 2007). 
Segundo o ponto de vista do éthos, a internacionalização é um processo de reforço do caráter internacional de uma universidade mediante o apoio de uma instituição líder (HANSON; MEYERSON, 1995; PICKERT; TURLINGTON, 1992).

Finalmente, na perspectiva do processo, a internacionalização é definida por Knight (1994) como um processo de integração da dimensão internacional/intercultural ao ensino, à pesquisa e aos serviços de uma universidade. Nessa definição, a internacionalização é caracterizada como um processo dinâmico que vai além da simples realização de atividades no âmbito internacional, considerando-se precário o uso desse critério como indicador do grau de internacionalização de uma instituição de Educação Superior. Segundo Miura (2006), a constatação do crescimento da mobilidade acadêmica de estudantes, professores e pesquisadores, o aumento do número de cursos, programas e qualificações com ênfase em temas internacionais e comparativos e a ênfase no desenvolvimento de competências internacionais e interculturais, entre outros elementos, levaram a essa mudança conceitual.

Em função das mudanças e dos desafios ocorridos com o processo de globalização e internacionalização das universidades e das sugestões de De Wit (2002), Knight (2003) redefine seu conceito de internacionalização formulado em 1994 e propõe um novo conceito, focando o processo e as mudanças. Para a autora, a internacionalização precisa ser compreendida nos níveis nacional, setorial e institucional. Portanto torna-se necessária uma nova definição que compreenda esses níveis e reflita as realidades atuais. Por outro lado, essa definição não deve especificar as razões, os benefícios, resultados, atores, atividades ou provedores da internacionalização, pois esses elementos variam de acordo com a nação e a instituição. É relevante a dimensão internacional em todos os aspectos da educação e o papel na sociedade.

Levando em conta todas essas premissas, Knight (2003, p. 2) propõe a seguinte definição: "Internacionalização nos níveis nacional, setorial e institucional é definida como o processo de integração de uma dimensão internacional, intercultural, ou global no propósito, nas funções ou na oferta de educação pós-secundária". Nessa definição, a autora destaca e explicita o sentido de alguns conceitos-chaves. Entre estes, cita os conceitos de processo, de dimensão internacional, intercultural ou global, de integração dessas dimensões nas políticas, nos programas curriculares e nos procedimentos e, por último, os conceitos de propósito, funções e oferta que devem ser considerados em conjunto. 
A internacionalização é um processo dinâmico, ou seja, um esforço continuado de mudança ou evolução, e não um conjunto de atividades isoladas. Ela compreende três dimensões - a internacional, a intercultural e a global, ou seja, as relações entre nações, culturas ou países. Na dimensão intercultural, a internacionalização também se refere à diversidade étnica/cultural dentro dos países, das comunidades e instituições. A dimensão global, embora controversa e eivada de críticas, é acrescentada para expressar o sentido de escopo mundial. Como enfatiza Knight (2003), há uma complementaridade entre esses três termos, que juntos expressam a riqueza da amplitude e profundidade da internacionalização.

O conceito de integração visa denotar o processo de incorporação da dimensão internacional e intercultural nas políticas e nos programas para assegurar que essa dimensão permaneça central e sustentável, e não apenas marginal. Knight (2003) propõe que os conceitos de propósito, funções e oferta sejam entendidos de forma articulada e esclarece seus significados.

Cabe ainda observar que Knight, em sua nova definição, incluiu também o que chamou de abordagem bottom-up e top-down (da base para o topo, do topo para a base) para incluir a influência importante do nível nacional/setorial na dimensão internacional da Educação Superior mediante a política, o financiamento e os marcos regulatórios.

Segundo Knight (2004), sua nova definição de internacionalização da Educação Superior não contradiz a anterior, mas apenas a explicita e refina com termos mais genéricos, tornando-a generalizável aos diferentes contextos educacionais nacionais e não especificando as razões, benefícios, resultados, atores, atividades e patrocinadores da internacionalização, que poderão ser peculiares em cada país. Posteriormente a essa definição, Knight (2011; 2012a), em dois textos breves, apresentou cinco mitos e cinco verdades que explicitam e esclarecem dimensões relevantes de sua definição de internacionalização da Educação Superior.

Knight (2012a, p. 1) chamou esses mitos de misconceptions, ou seja, concepções equivocadas ou erradas sobre internacionalização. Ao elenco de Knight, Hans de Wit, atual diretor do Center for International Higher Education, do Boston College, nos Estados Unidos, acrescentou nove concepções equivocadas ou enganosas sobre a internacionalização da Educação Superior. De seu elenco, apenas duas têm semelhança com dois dos cinco mitos (1 e 3) descritos por 
Knight. As nove pseudoconcepções de internacionalização da Educação Superior apontadas por De Wit (2011) são as seguintes: 1) A internacionalização é ensino no idioma inglês; 2) A internacionalização é ensino de um curso internacional; 3) A internacionalização é igual a cumprir um programa de estudos com assuntos internacionais; 4) A internacionalização significa ter muitos estudantes internacionais matriculados na instituição; 5) A internacionalização pode implantar-se com êxito com apenas uns poucos estudantes internacionais em sala de aula; 6) Não há necessidade de se avaliarem as competências interculturais e internacionais necessariamente com tais; 7) Quanto mais acordos tem, mais internacionalizada é a instituição; 8) A Educação Superior é internacional por sua própria natureza; 9) A internacionalização é um objetivo em si mesmo.

Knight (2012a) propôs cinco verdades ou princípios que podem contribuir para esclarecer e iluminar o conceito e a prática de internacionalização nas Instituições de Educação Superior. Essas verdades podem ser formuladas nos seguintes termos (Knight, 2012a): 1) A internacionalização deve respeitar e complementar a dimensão local; 2) A internacionalização é um processo adaptável ao perfil de cada instituição ou país; 3) No processo de internacionalização, há benefícios, riscos e consequências não intencionadas; 4) A internacionalização não é um fim em si mesmo; 5) Globalização e internacionalização são diferentes, mas associadas.

Recentemente, como produto adicional de estudo ao Parlamento Europeu, para identificar tendências-chave nas estratégias nacionais correntes de internacionalização na Europa e no resto do mundo e para delinear um cenário para o futuro da internacionalização da Educação Superior na Europa, De Wit e Hunter (2015) propuseram uma revisão da definição de internacionalização de Jane Knight comumente aceita entre os especialistas da área. A definição proposta ficou assim formulada: Internacionalização é

[...] o processo intencional de integração de uma dimensão internacional, intercultural ou global no propósito, nas funções e na oferta de educação pós-secundária, a fim de aprimorar a qualidade da educação e da pesquisa para todos os estudantes e corpo docente e fornecer uma contribuição significativa para a sociedade. (DE WIT; HUNTER, 2015, p. 3, grifos do autor).

A internacionalização da Educação Superior como um processo intencional está se tornando a política dominante nos níveis nacional e institucional em muitos 
países do mundo e, em especial, na Europa. No entanto, mesmo na Europa, vista como um caso de melhor prática de internacionalização, De Wit e Hunter (2015) reconhecem que ainda há muito a ser feito e um grau variado de sucesso e sérios desafios a serem superados no sul, centro e leste da Europa. Outro elemento enfatizado na definição de internacionalização da Educação Superior por De Wit e Hunter é que ela não é um fim em si mesmo, mas um meio para aprimorar a qualidade da educação e da pesquisa, e que não deveria se basear somente na justificativa econômica.

A inclusão da internacionalização "em casa" (at home) como um novo pilar na estratégia de internacionalização abrirá uma nova frente nas políticas de internacionalização da Educação Superior, tanto no nível nacional como no institucional, para se efetivar concretamente. Essa nova perspectiva vem se justificando para possibilitar a democratização mais efetiva da internacionalização, pois em geral os estudantes que disputam as bolsas para o acesso à mobilidade já detêm vantagens socioeconômicas e culturais em seu próprio país.

Antes de De Wit e Hunter (2015), Knight (2012b) já havia proposto a conceptualização da internacionalização como tendo dois pilares intimamente relacionados e interdependentes - o doméstico (at home, em casa) e o exterior (abroad, além fronteira, transfronteira ou transnacional). Por isso, Knight distingue dois tipos básicos de internacionalização: a internacionalização "em casa" ou doméstica e a internacionalização no exterior ou "educação transfronteira". Para a autora, a dimensão internacional do currículo, como uma das expressões da internacionalização em casa, está avançando para a integração das perspectivas internacional, global, intercultural e comparada no processo de ensino e aprendizagem e nos conteúdos programáticos. A inclusão de conhecimentos, habilidades e valores internacionais e interculturais constitui uma nova ênfase curricular. A internacionalização no exterior ou transfronteira tem implicações significativas para a internacionalização baseada no campus da universidade e vice-versa. A mobilidade estudantil, como parte da "educação além-fronteira", segundo Knight (2012b), é a grande corrida de cérebros (great brain race) do século XXI, com implicações para ganho cerebral, evasão de cérebros e treinamento cerebral (brain gain, brain drain, brain train). 


\section{RAZÕES DA INTERNACIONALIZAÇÃO DA EDUCAÇÃO SUPERIOR}

As razões ou justificativas para a busca da internacionalização da Educação Superior nos países e nas próprias instituições universitárias têm sido múltiplas e diferenciadas para países e instituições. Knight e De Wit (1995) classificam essas razões em duas grandes categorias: (1) razões políticas e econômicas e (2) razões culturais e educacionais. Em estudo posterior, Knight (1997) reclassifica essas razões em quatro categorias: (1) política; (2) econômica; (3) sociocultural; e (4) acadêmica.

Segundo De Wit (apud MIURA, 2006), essa reclassificação permite uma reorganização mais adequada das principais razões que, segundo Knight (2005), impulsionam a internacionalização da Educação Superior. À razão política estão relacionadas a política externa, a segurança nacional, a cooperação para o desenvolvimento, a paz e o entendimento mútuo, a identidade nacional e regional. Esse tipo de justificativa é especialmente alegado pelos governantes para adotar uma política nacional de internacionalização da Educação Superior ao reconhecer que seus benefícios são superiores aos seus custos. Em geral, essa razão política é considerada mais importante no nível nacional do que no internacional. À razão econômica vinculam-se a competitividade, o crescimento econômico, o mercado de trabalho, a demanda nacional por educação e os incentivos financeiros para as instituições e governos. Essa razão econômica tem importância e relevância crescentes nos países desenvolvidos que, para aprimorar e manter vantagem competitiva na economia globalizada, procuram desenvolver uma força de trabalho altamente qualificada e competitiva, investir em pesquisa aplicada e vender serviços educacionais para estudantes de países estrangeiros. À razão sociocultural relacionam-se o desenvolvimento social e comunitário, o entendimento intercultural e o vínculo com a identidade cultural. A atual economia globalizada e o sistema de informação e comunicação têm impactado e afetado a razão sociocultural. À razão acadêmica vinculam-se a promoção da dimensão internacional da pesquisa, do ensino e da extensão, o desenvolvimento da instituição, a reputação e o status internacional, a melhoria da qualidade e os padrões acadêmicos internacionais. Ela se liga diretamente com o aprimoramento da docência, do processo de aprendizagem e da pesquisa. Segundo Knight (1999), esses quatro tipos de razões não são totalmente distintos ou exclusivos, poden- 
do mudar ou evoluir em resposta às necessidades e prioridades cambiantes dos países e das instituições.

Cinco têm sido as razões para justificar a adesão à internacionalização da Educação Superior no nível institucional e cinco no nível nacional (KNIGHT, 2004). Essas razões estão sintetizadas no Quadro 2.

Quadro 2- Razões da internacionalização nos níveis nacional e institucional

\begin{tabular}{|l|l|}
\hline Nível & Razões \\
\hline Nacional & Desenvolvimento de recursos humanos \\
& Alianças estratégicas \\
& Transação comercial \\
& Construção da nação \\
& Desenvolvimento social/cultural \\
\hline Institucional & Reputação e perfil institucional \\
& Geração de receita \\
& Desenvolvimento de estudantes e professores \\
& Alianças estratégicas \\
& Produção do conhecimento \\
\hline
\end{tabular}

Fonte: Knight (2004, p. 23).

Para tornar mais claras e explícitas as alegadas razões da internacionalização da Educação Superior, tanto no nível nacional como no institucional, Knight (2004) apresenta breve descrição de como elas são entendidas pelos governantes ou pelas Instituições de Educação Superior. No nível nacional, o desenvolvimento de recursos humanos se dará por meio de estratégias, de recrutamento e incentivo à permanência e à formação de quadro humano de alto nível intelectual e intercultural capaz de contribuir para o desenvolvimento do país. As alianças estratégicas bilaterais ou multilaterais poderão contribuir para a melhoria do ensino e o desenvolvimento de pesquisa conjunta, tornando o sistema de Educação Superior mais competitivo e gerando benefícios culturais, políticos e econômicos para o país.

No nível institucional, a reputação e o perfil institucional relacionam-se aos propósitos econômico, político, social e acadêmico. O renome da instituição no contexto regional e global pode levá-la a mudar as estratégias adotadas e as razões da internacionalização. Os rankings internacionais vêm afetando o reconhe- 
cimento das instituições e seu crescimento em resposta à demanda internacional. O desenvolvimento de estudantes e professores em universidades estrangeiras poderá contribuir para a formação adequada de pessoal com as competências demandadas nos níveis local e global.

Mais recentemente, outras razões para internacionalizar uma instituição de educação são apontadas por Marmolejo (2010) e por Hénard, Diamond e Roseveare (2012). Marmolejo (2010) identifica cinco razões, em ordem de importância: aprimorar a preparação do estudante; internacionalizar o currículo; elevar o perfil internacional da instituição; fortalecer a pesquisa e a produção de conhecimento; e diversificar seu corpo docente e de funcionários.

O Quadro 3, adaptado de Lima e Contel (2009) por Mueller (2013), sintetiza as informações básicas referentes aos programas, provedores e motivações dos quatro períodos da internacionalização da Educação Superior brasileira.

Quadro 3 - Períodos, programas, provedores e motivações da internacionalização da Educação Superior brasileira

\begin{tabular}{|c|c|c|c|}
\hline Períodos & rograma & Provedores & Motivação \\
\hline $\begin{array}{l}\text { 10 } \\
\text { Período: } \\
\text { Anos } \\
1930 \text { e } \\
1950\end{array}$ & $\begin{array}{l}\text { - Programa de cooperação aca- } \\
\text { dêmica internacional com ênfase } \\
\text { nas missões que traziam profes- } \\
\text { sores }\end{array}$ & $\begin{array}{l}\text { - Universidades } \\
\text { estrangeiras e } \\
\text { brasileiras }\end{array}$ & $\begin{array}{l}\text { - Acadêmica: fortale- } \\
\text { cimento do projeto } \\
\text { acadêmico das uni- } \\
\text { versidades emergen- } \\
\text { tes }\end{array}$ \\
\hline $\begin{array}{l}\text { 2o Perío- } \\
\text { do: anos } \\
1960 \text { e } \\
1970\end{array}$ & $\begin{array}{l}\text { - Programa de cooperação aca- } \\
\text { dêmica internacional com ênfase } \\
\text { na presença de consultores e na } \\
\text { concessão de bolsas de estudos } \\
\text { para realizar mestrado/doutora- } \\
\text { do no exterior }\end{array}$ & $\begin{array}{l}\text { - Agências inter- } \\
\text { nacionais e go- } \\
\text { verno brasileiro } \\
\text { - Agências nacio- } \\
\text { nais e internacio- } \\
\text { nais }\end{array}$ & $\begin{array}{l}\text { - Político-acadêmica: } \\
\text { reestruturação do } \\
\text { sistema de Educação } \\
\text { Superior em conso- } \\
\text { nância com o "mo- } \\
\text { delo americano" }\end{array}$ \\
\hline
\end{tabular}




\begin{tabular}{|c|c|c|c|}
\hline Períodos & Programa & Provedores & Motivação \\
\hline $\begin{array}{l}\text { 3o Perío- } \\
\text { do: anos } \\
1980 \text { e } \\
1990\end{array}$ & $\begin{array}{l}\text { - Programa de cooperação aca- } \\
\text { dêmica internacional com ênfase } \\
\text { na formação de grupos de estu- } \\
\text { do e pesquisa em torno de temas } \\
\text { de interesse compartilhado } \\
\text { - Concessão de bolsas de estudos } \\
\text { para realizar doutorado no exte- } \\
\text { rior, em áreas classificadas como } \\
\text { estratégicas } \\
\text { - Programa de cooperação acadê- } \\
\text { mica internacional com ênfase na } \\
\text { vinda de professores visitantes e } \\
\text { na ida de estudantes para realiza- } \\
\text { ção de poucas disciplinas }\end{array}$ & $\begin{array}{l}\text { - Agências inter- } \\
\text { nacionais e go- } \\
\text { verno brasileiro } \\
\text { - Agências nacio- } \\
\text { nais e internacio- } \\
\text { nais } \\
\text { - Universidades } \\
\text { estrangeiras e } \\
\text { instituições bra- } \\
\text { sileiras de Edu- } \\
\text { cação Superior } \\
\text { privadas }\end{array}$ & $\begin{array}{l}\text { - Acadêmico-merca- } \\
\text { dológica: } \\
\text { a) Expansão e conso- } \\
\text { lidação dos progra- } \\
\text { mas de pós-gradua- } \\
\text { ção stricto sensu } \\
\text { b) Incremento das } \\
\text { pesquisas de ponta } \\
\text { em áreas estratégicas } \\
\text { c) Diferencial com- } \\
\text { petitivo de algumas } \\
\text { instituições ou de } \\
\text { alguns cursos }\end{array}$ \\
\hline $\begin{array}{l}\text { 4o Perío- } \\
\text { do: anos } \\
2000\end{array}$ & $\begin{array}{l}\text { - Programa de cooperação acadê- } \\
\text { mica internacional com ênfase na } \\
\text { formação de grupos de estudos } \\
\text { e pesquisa em torno de temas } \\
\text { estratégicos e de interesse parti- } \\
\text { Ihado } \\
\text { - Concessão de bolsas de estudos } \\
\text { para realizar doutorado no exte- } \\
\text { rior, em áreas classificadas como } \\
\text { estratégicas e sem tradição de } \\
\text { pesquisa no país } \\
\text { - Programa de cooperação aca- } \\
\text { dêmica internacional com ênfase } \\
\text { na vinda de professores visitan- } \\
\text { tes e na ida de estudantes para } \\
\text { realização de poucas disciplinas } \\
\text { - Projeto de criação de universi- } \\
\text { dades federais orientadas pela } \\
\text { internacionalização ativa } \\
\text { - Comercialização de serviços } \\
\text { educacionais. }\end{array}$ & $\begin{array}{l}\text { - Agências inter- } \\
\text { nacionais e go- } \\
\text { verno brasileiro } \\
\text { - Agências nacio- } \\
\text { nais e internacio- } \\
\text { nais } \\
\text { - Universidades } \\
\text { estrangeiras e } \\
\text { instituições bra- } \\
\text { sileiras de Edu- } \\
\text { cação Superior } \\
\text { privadas } \\
\text { - Corporações } \\
\text { internacionais } \\
\text { - Universidades } \\
\text { corporativas }\end{array}$ & $\begin{array}{l}\text { - Acadêmica, política, } \\
\text { econômica e merca- } \\
\text { dológica } \\
\text { a) Inserção interna- } \\
\text { cional dos progra- } \\
\text { mas de pós-gradua- } \\
\text { ção stricto sensu } \\
\text { b) Incremento das } \\
\text { pesquisas de ponta } \\
\text { em áreas estratégi- } \\
\text { cas } \\
\text { c) Incremento re- } \\
\text { gional de caráter } \\
\text { inclusivo } \\
\text { d) Diferencial de } \\
\text { algumas instituições } \\
\text { ou de alguns cursos } \\
\text { e) Captação de estu- } \\
\text { dantes }\end{array}$ \\
\hline
\end{tabular}

Fonte: Mueller (2013), adaptado de Lima e Contel (2009). 


\section{ESTRATÉGIAS DE INTERNACIONALIZAÇÃO DA EDUCAÇÃO SUPERIOR}

Um conjunto de normas e diretrizes que apresentam as prioridades da instituição caracteriza sua política de internacionalização. A formulação dessa política em geral está presente na missão e nos valores da instituição de Educação Superior. Tradicionalmente, como observa Knight (2005), a internacionalização em nível institucional tem-se traduzido num conjunto de estratégias e atividades que operacionalizam a sua política institucional.

Estratégias são elementos do planejamento institucional destinados a tornar efetivo o processo de internacionalização da Educação Superior. As estratégias e atividades constituem a dimensão mais operacional no contexto da internacionalização da Educação Superior no nível institucional. Esse termo passou a ganhar destaque quando Knight e De Wit (1997) ampliaram o conceito de internacionalização da Educação Superior e passaram a defini-la como um processo que compreende estratégias programáticas e estratégias organizacionais que devem se integrar ao plano de desenvolvimento institucional e à cultura da instituição. Na escolha e definição dessas estratégias, pondera Knight (2004), a universidade deve vinculá-las às razões para a adoção da política de internacionalização e às suas particularidades específicas.

Knight (2004) classificou as estratégias de internacionalização da Educação Superior em duas categorias - as estratégias programáticas e as estratégias organizacionais. As estratégias programáticas abrangem quatro subcategorias: programas acadêmicos; pesquisa e colaboração científica; atividades nacionais e internacionais (domésticas e estrangeiras); e atividades extracurriculares. As estratégias organizacionais também compreendem quatro subcategorias: governança; operações; serviços; e recursos humanos. No Quadro 4, a autora apresenta as atividades pertinentes a cada subcategoria de estratégia. 
Quadro 4- Categorias de estratégias programáticas e organizacionais de internacionalização no nível institucional

\begin{tabular}{|c|c|}
\hline \multicolumn{2}{|r|}{ ESTRATÉGIAS PROGRAMÁTICAS } \\
\hline $\begin{array}{l}\text { Programas aca- } \\
\text { dêmicos }\end{array}$ & $\begin{array}{l}\text { - Intercâmbios de estudantes } \\
\text { - Estudo de idiomas estrangeiros } \\
\text { - Dimensão internacional do currículo } \\
\text { - Estudos temáticos } \\
\text { - Trabalho/estudo no exterior } \\
\text { - Processo de ensino-aprendizagem } \\
\text { - Programas de duplo diploma } \\
\text { - Treinamento intercultural } \\
\text { - Mobilidade de docentes/funcionários } \\
\text { - Professores e palestrantes visitantes }\end{array}$ \\
\hline $\begin{array}{l}\text { Pesquisa e co- } \\
\text { laboração cien- } \\
\text { tífica }\end{array}$ & $\begin{array}{l}\text { - Área e centros temáticos } \\
\text { - Projetos de pesquisa conjunta } \\
\text { - Conferências e seminários internacionais } \\
\text { - Artigos e trabalhos publicados } \\
\text { - Acordos internacionais de pesquisa } \\
\text { - Programas de intercâmbio para pesquisa }\end{array}$ \\
\hline $\begin{array}{l}\text { Atividades } \\
\text { nacionais e } \\
\text { transnacionais } \\
\text { (domésticas e } \\
\text { estrangeiras) }\end{array}$ & $\begin{array}{l}\text { - Parcerias com grupos de organizações não governamentais ou } \\
\text { grupos do setor público-privado } \\
\text { - Serviço comunitário e projeto de trabalho intercultural } \\
\text { - Vínculos, parcerias internacionais e redes } \\
\text { - Treinamento e programas de pesquisa } \\
\text { - Programa a ex-alunos no exterior }\end{array}$ \\
\hline \multicolumn{2}{|r|}{ ESTRATÉGIAS ORGANIZACIONAIS } \\
\hline Governança & $\begin{array}{l}\text { - Compromisso expresso por líderes } \\
\text { - Envolvimento ativo do corpo docente } \\
\text { - Razões e objetivos para a internacionalização bem articulados } \\
\text { - Reconhecimento da dimensão internacional na missão, no plane- } \\
\text { jamento e nos documentos de política }\end{array}$ \\
\hline Operações & $\begin{array}{l}\text { - Vinculado ao planejamento, orçamento e sistemas de revisão de } \\
\text { qualidade em nível institucional e departamental } \\
\text { - Estruturas organizacionais apropriadas: sistemas formais e infor- } \\
\text { mais para comunicação, ligação e coordenação } \\
\text { - Equilíbrio entre promoção centralizada e descentralizada e gestão } \\
\text { da internacionalização } \\
\text { - Apoio financeiro adequado e sistemas de alocação de recursos }\end{array}$ \\
\hline
\end{tabular}




\begin{tabular}{|l|l|}
\hline Serviços & - Apoio de unidades de serviços da instituição: acomodação para \\
& estudantes, tecnologia da informação \\
& - Envolvimento de unidades de apoio acadêmico: biblioteca, ensi- \\
& no e aprendizado, desenvolvimento do currículo, treinamento dos \\
docentes & - Serviços de apoio estudantil para estudantes recebidos e envia- \\
dos: programas de orientação, conselheiros, treinamento transcul- \\
tural, conselhos sobre vistos
\end{tabular}

Fonte: Knight (2004, p. 14).

Visando construir um modelo de indicadores para abarcar o processo de internacionalização nas Instituições de Educação Superior nas suas mais variadas formas de atividades, Brandenburg e Federkeil (2007) propõem a organização de três grandes categorias principais de indicadores, ou seja, os aspectos gerais, a pesquisa acadêmica e o ensino e estudo. A categoria "aspectos gerais" compreende cinco subcategorias: gestão geral, professores, jovens pesquisadores, candidatos de doutorado e pós-doutorado, técnico administrativo, recursos e rede internacional (RI). A categoria "pesquisa acadêmica" abrange seis subcategorias: professores, rede internacional em pesquisa, recursos, projeto de pesquisa internacional, resultados de pesquisa e jovem pesquisador. A categoria "ensino e estudo" explicita-se em oito subcategorias: professores, estudantes de graduação e de pós-graduação, serviço e administração, rede internacional para ensino e aprendizagem, recursos, programas de estudo/currículo, graduados e reputação internacional. O elenco de indicadores para cada categoria e respectivas subcategorias é apresentado no Quadro 5. 
Quadro 5- Modelo de indicadores de internacionalização

\begin{tabular}{|c|c|}
\hline \multicolumn{2}{|r|}{ ASPECTOS GERAIS } \\
\hline Gestão em geral & $\begin{array}{l}\text { - Relação do gestor com a internacionalização } \\
\text { - Ações do gestor priorizam e/ou incentivam a internacionaliza- } \\
\text { ção }\end{array}$ \\
\hline Professores & $\begin{array}{l}\text { - Experiência e formação internacional dos professores } \\
\text { - Recrutamento de professores internacionais } \\
\text { - Professor visitante }\end{array}$ \\
\hline $\begin{array}{l}\text { Jovens pesquisado- } \\
\text { res, candidatos de } \\
\text { doutorado e pós- } \\
\text {-doutorado }\end{array}$ & $\begin{array}{l}\text { - Experiência e formação no exterior } \\
\text { - Candidatos do exterior }\end{array}$ \\
\hline \begin{tabular}{|l|} 
Técnico- \\
administrativo
\end{tabular} & $\begin{array}{l}\text { - Conhecimento de língua estrangeira } \\
\text { - Participação em programa de intercâmbio internacional } \\
\text { - Número de empregados no exterior de RI ou equivalente }\end{array}$ \\
\hline Recursos & $\begin{array}{l}\text { - Orçamento para cooperação internacional com proporção do } \\
\text { total de IES } \\
\text { - Número de funcionários/vagas para atender RI }\end{array}$ \\
\hline Rede internacional & $\begin{array}{l}\text { - Parcerias ativas } \\
\text { - Participações em eventos internacionais } \\
\text { - Membro de redes internacionais } \\
\end{array}$ \\
\hline \multicolumn{2}{|r|}{ PESQUISA ACADÊMICA } \\
\hline Professores & $\begin{array}{l}\text { - Experiência e formação internacional dos professores } \\
\text { - Recrutamento de professores internacionais } \\
\text { - Professor visitante }\end{array}$ \\
\hline $\begin{array}{l}\text { Rede internacional } \\
\text { em pesquisa }\end{array}$ & $\begin{array}{l}\text { - Fundos externos } \\
\text { - Recursos derivados de projetos com parceria internacional } \\
\text { - Número de comitês e atividades, associações profissionais in- } \\
\text { ternacionais } \\
\text { - Número de edições de periódicos internacionais } \\
\text { - Número de doutorados internacionais }\end{array}$ \\
\hline Recursos & $\begin{array}{l}\text { - Orçamento de cooperação de pesquisa internacional e bolsas } \\
\text { para doutorado } \\
\text { - Bolsas ofertadas pela IES para candidatos internacionais ao dou- } \\
\text { torado }\end{array}$ \\
\hline $\begin{array}{l}\text { Projeto de pesqui- } \\
\text { sa internacional }\end{array}$ & $\begin{array}{l}\text { - Número de projetos com parceria internacional } \\
\text { - Número de pesquisadores envolvidos em projeto de pesquisa } \\
\text { com cooperação internacional } \\
\text { - Número de projetos com fundos internacionais }\end{array}$ \\
\hline
\end{tabular}




\begin{tabular}{|c|c|}
\hline $\begin{array}{l}\text { Resultados da pes- } \\
\text { quisa }\end{array}$ & $\begin{array}{l}\text { - Número de publicações internacionais por pesquisador } \\
\text { - Número de citações por "paper" } \\
\text { - Número de contribuições em conferências internacionais por } \\
\text { professor } \\
\text { - Número de patentes internacionais por professor }\end{array}$ \\
\hline Jovem pesquisador & $\begin{array}{l}\text { - Experiência e formação no exterior } \\
\text { - Número de duplo diploma }\end{array}$ \\
\hline \multicolumn{2}{|r|}{ ENSINO E ESTUDO } \\
\hline Professores & $\begin{array}{l}\text { - Número de professores que lecionam disciplina em língua es- } \\
\text { trangeira } \\
\text { - Número de professores que passam ao menos um semestre no } \\
\text { exterior } \\
\text { - Atividade no exterior como visitante } \\
\text { - Formação de doutorado no exterior } \\
\text { - Experiência profissional no exterior } \\
\text { - Recrutamento de outras nacionalidades }\end{array}$ \\
\hline $\begin{array}{l}\text { Estudantes (gra- } \\
\text { duação e pós-gra- } \\
\text { duação) }\end{array}$ & $\begin{array}{l}\text { - Número de estudantes internacionais } \\
\text { - Número de estudantes de IES no exterior } \\
\text { - Número de estudantes de duplo diploma } \\
\text { - Estágio internacional }\end{array}$ \\
\hline $\begin{array}{l}\text { Serviço e adminis- } \\
\text { tração }\end{array}$ & $\begin{array}{l}\text { - Número de postos para auxílio a estudantes de intercâmbio } \\
\text { - Centro de orientação internacional } \\
\text { - Funcionários internacionais } \\
\text { - Aulas de aprendizagem intercultural } \\
\text { - Informações sobre países/culturas }\end{array}$ \\
\hline $\begin{array}{l}\text { Rede internacio- } \\
\text { nal para ensino e } \\
\text { aprendizagem }\end{array}$ & $\begin{array}{l}\text { - Número de estudantes em intercâmbio in e out } \\
\text { - Número de estudantes em in e out relativo ao número de acor- } \\
\text { dos } \\
\text { - Membro ativo de associações especializadas em rede interna- } \\
\text { cional }\end{array}$ \\
\hline Recursos & $\begin{array}{l}\text { - Bolsas para período no exterior } \\
\text { - Orçamento para marketing em internacionalização, comparado } \\
\text { ao orçamento total } \\
\text { - Fundos para aulas de visitantes } \\
\text { - Fundos e suporte para estadas próprias no exterior }\end{array}$ \\
\hline $\begin{array}{l}\text { Programas de estu- } \\
\text { do/currículo }\end{array}$ & $\begin{array}{l}\text { - Proporção de cursos ofertados em língua estrangeira } \\
\text { - Currículos internacionais } \\
\text { - Número de línguas estrangeiras ofertadas } \\
\text { - Reconhecimento de créditos no exterior } \\
\text { - Ofertas de programas sobre interculturalidade }\end{array}$ \\
\hline
\end{tabular}




\begin{tabular}{|l|l|}
\hline Graduados & $\begin{array}{l}\text { - Egressos com duplo diploma } \\
\text { - Egressos graduados de outra nacionalidade } \\
\text { - Informações sobre desenvolvimento profissional dos graduados }\end{array}$ \\
\hline $\begin{array}{l}\text { Reputação interna- } \\
\text { cional }\end{array}$ & \begin{tabular}{l} 
- Número de publicações internacionais por programa de estudantes internacionais \\
\hline
\end{tabular}
\end{tabular}

Fonte: Mueller (2013), adaptado de Brandenburg e Federkeil (2007).

Para Brandenburg e Federkeil (2007), essa lista de indicadores pode ajudar na elaboração de estratégias institucionais, permitindo possíveis adaptações à realidade de cada instituição. Os autores lembram também que diferentes organismos nacionais ou internacionais podem propor indicadores de internacionalização que são baseados em realidades distintas e que, por isso, podem ser inadequados para a avaliação do processo de internacionalização de um determinado contexto nacional.

Entre os três conhecidos instrumentos de classificação internacional de Instituições de Educação Superior - Times Higher Education Suplement (THES); Academic Ranking of World Universities (ARWU), utilizado pela Universidade Jiao Tong de Xangai; e Webometrics Ranking (WM), usado pelo Cybermetrics Lab -, apenas o primeiro inclui a variável internacionalização entre seus critérios e traz dois indicadores relacionados a essa variável. O Quadro 6 apresenta uma visão geral da metodologia da classificação do THES.

Quadro 6- Visão geral da metodologia da classificação do THES

\begin{tabular}{|l|l|l|c|}
\hline \multicolumn{1}{|c|}{ Critérios } & \multicolumn{1}{|c|}{ Indicador } & \multicolumn{1}{c|}{ Explicação } & Peso \\
\hline \multirow{2}{*}{$\begin{array}{l}\text { Qualidade } \\
\text { da pesquisa }\end{array}$} & $\begin{array}{l}\text { Revisão por } \\
\text { pares, acadêmica } \\
\text { e global }\end{array}$ & $\begin{array}{l}\text { Pontuação composta a partir do } \\
\text { questionário por pares }\end{array}$ & $40 \%$ \\
\cline { 2 - 4 } & $\begin{array}{l}\text { Citações } \\
\text { por docente }\end{array}$ & $\begin{array}{l}\text { Pontuação baseada na pesquisa em } \\
\text { relação com o tamanho do corpo de } \\
\text { pesquisadores }\end{array}$ & $20 \%$ \\
\hline $\begin{array}{l}\text { Qualidade } \\
\text { do ensino }\end{array}$ & $\begin{array}{l}\text { Razão alunos/ } \\
\text { professores }\end{array}$ & $\begin{array}{l}\text { Pontuação baseada na razão alunos/ } \\
\text { professores }\end{array}$ & $20 \%$ \\
\hline $\begin{array}{l}\text { Empregabilidade } \\
\text { dos graduados }\end{array}$ & $\begin{array}{l}\text { Revisão sobre o } \\
\text { emprego global }\end{array}$ & $\begin{array}{l}\text { Pontuação baseada nas respostas ao } \\
\text { questionário de empregadores }\end{array}$ & $10 \%$ \\
\hline
\end{tabular}




\begin{tabular}{|c|l|l|c|}
\hline Critérios & \multicolumn{1}{|c|}{ Indicador } & \multicolumn{1}{|c|}{ Explicação } & Peso \\
\hline \multirow{5}{*}{ Internacionalização } & $\begin{array}{l}\text { Professorado } \\
\text { internacional }\end{array}$ & $\begin{array}{l}\text { Pontuação baseada na proporção de } \\
\text { professorado internacional }\end{array}$ & $5 \%$ \\
\cline { 2 - 4 } & $\begin{array}{l}\text { Alunado } \\
\text { internacional }\end{array}$ & $\begin{array}{l}\text { Pontuação baseada na proporção de } \\
\text { alunado internacional }\end{array}$ & $5 \%$ \\
\hline
\end{tabular}

Fonte: Delgado-Márquez; Hurtado-Torres; Bondar (2011, p. 108).

\section{5 À GUISA DE CONCLUSÃO}

O processo de internacionalização da Educação Superior vem crescendo de maneira acelerada, levando à sua periódica reconceitualização para abranger dimensões inexploradas, pouco valorizadas ou pouco claras dessa nova função da universidade contemporânea. Ao lado do crescimento da internacionalização por mobilidade acadêmica de estudantes e docentes em consequência das políticas nacionais fundadas na expectativa de uma economia do futuro baseada no conhecimento, torna-se necessário implementar com mais densidade a internacionalização em casa a fim de tornar acessíveis a todos os estudantes os benefícios da internacionalização em termos de conhecimentos, habilidades e valores internacionais e interculturais necessários aos jovens no futuro para sua efetiva integração ao mercado de trabalho numa economia crescentemente globalizada.

A internacionalização da Educação Superior como instrumento de cooperação dos países desenvolvidos aos países em desenvolvimento por razões acadêmicas, culturais e políticas vem evoluindo para a internacionalização por razões econômicas para oferta de serviços educacionais como "mercadoria" cara a ser vendida aos países menos desenvolvidos. A consequência desse movimento tem sido a internacionalização como competição por mercados educacionais, o ranqueamento da excelência das universidades como instrumento de marketing educacional, o capitalismo acadêmico, o produtivismo acadêmico, a competição acadêmica dentro das próprias universidades, a busca de financiamento privado da pesquisa acadêmica e o entendimento da Educação Superior como bem privado. O objetivo da melhoria da excelência acadêmica das universidades pela via da cooperação acadêmica arrisca desvirtuar-se na sua batalha por fins mais nobres. 
As estratégias programáticas e organizacionais de internacionalização da Educação Superior, seja para a via transfronteira, seja para a via doméstica, precisam ser definidas mediante indicadores operacionais de sua implementação, a fim de poderem ser avaliadas periodicamente, com base em critérios claros e definidos dessa política. A implementação efetiva dessa política implica no comprometimento efetivo, seja no nível estatal, seja no nível institucional, com a incorporação explícita da dimensão da internacionalização nos propósitos e nas funções atuais da universidade contemporânea.

\section{REFERÊNCIAS}

ARUM, Stephen; VAN DE WATER, Jack. The need for a definition of international education in US universities. In: KLASEK, Charles B. (Ed.). Bridges to the future: strategies for internationalizing Higher Education. Carbondale: Association of International Education Administrators, 1992. p. 191-203.

AYOUBI, Rami M.; MASSOUD, Hiba K. The strategy of internationalization in Universities. International Journal of Educational Management, v. 21, n. 4, p. 339-49, 2007.

BRANDENBURG, Uwe; FEDERKEIL, Gero. How to measure internationality and internationalization of Higher Education institutions: indicators and key figures. Working paper n. 92. Berlin: Centre for Higher Education Development, 2007.

DELGADO-MÁRQUEZ, Blanca L.; HURTADO-TORRES, Nuria Ester; BONDAR, Yarslava. La internacionalización en la Enseñanza Superior: investigación teórica y empírica sobre su influencia en las clasificaciones de las instituciones universitarias. Revista de Universidad y Sociedad del Conocimiento, Barcelona, v. 8, n. 2, p. 101-20, jul. 2011.

DE WIT, Hans; HUNTER, Fiona. The future of internationalization of Higher Education. International Higher Education, Boston, n. 83, p. 23, 2015. Disponível em: https:// ejournals.bc.edu/ojs/index.php/ihe/article/view/9073 Acesso em: 10 mar. 2017.

DE WIT, Hans. Internationalization of Higher Education: nine misconceptions. International Higher Education, Boston, n. 64, Summer, p. 6-7, 2011. Disponível em: https://ejournals. bc.edu/ojs/index.php/ihe/article/view/8556/8321. Acesso em: 10 mar. 2017.

DE WIT, Hans. Internationalization of Higher Education in the United States of America and Europe: a historical comparative and conceptual analysis. Westport, CT: Greenwood Press, 2002. 
ELKIN, Graham; FARMSWORTH, John; TEMPLER, Andrew. Strategy and the internationalization of Universities. International Journal of Educational Management, v. 22 , n. 3, p. 239-50, 2008.

GREEN, Madeleine F.; OLSON, Christa. Internationalizing the campus: a strategic approach. International Educator, v. XII, n. 1, p. 13-21, 2003.

GREEN, Madeleine F.; SHOENBERG, Robert. Where faculty live: internationalizing the disciplines. Washington, DC: American Council on Education, 2006.

HANSON, Katharine; MEYERSON, Joel. International challenges to American Colleges and Universities: looking ahead. Phoenix, AZ: American Council on Education and The Oryx Press, 1995.

HARARI, Maurice. The internationalization of the curriculum. In: KLASEK, Charles B. (Ed.). Bridges to the future: strategies for internationalizing Higher Education. Carbondale, IL: Association of International Education Administrators, 1992. p. 52-79.

HÉNARD, Fabrice; DIAMON, Leslie; ROSEVEARE, Debora. Approaches to internationalisation and their implications for strategic management and institutional practice: a guide for Higher Education institutions. OECD Higher Education Programme IMHE, 2012. Disponível em: https://www.oecd.org/edu/imhe/Approaches\%20to\%20internationalisation\%20-\%20 final\%20-\%20web.pdf. Acesso em: 15 jul. 2016.

JAVALGI, Rajshekhar G.; GRIFFITH, David A.; WHITE, D. Steven. An empirical examination of factors influencing the internationalization of service firms. Journal of Services Marketing, v. 17, n. 2, p. 185-201, 2003.

KLASEK, Charles B. (Ed.). Bridges to the future: strategies for internationalizing Higher Education. Carbondale, IL: Association of International Education Administrators, 1992.

KNIGHT, Jane. Five truths about internationalization. International Higher Education, Boston, n. 69, p. 1-4. Fall, 2012a. Disponível em: https://ejournals.bc.edu/ojs/index.php/ ihe/article/view/8644/7776. Acesso em: 10 nov. 2016.

KNIGHT, Jane. Student mobility and internationalization: trends and tribulations. Research in Comparative and International Education, v. 7, n. 1, p. 20-33, 2012b. DOI: http://dx.doi. org/10.2304/rcie.2012.7.1.20. Acesso em: 10 nov. 2016.

KNIGHT, Jane. Five myths about internationalization. International Higher Education, Boston, n. 62, p. 14-5, Winter, 2011. Disponível em: https://ejournals.bc.edu/ojs/index. php/ihe/article/view/8532/7666. Acesso em: 10 nov. 2016. 
KNIGHT, Jane. Un modelo de internacionalización: respuesta a nuevas realidades y retos. In: DE WIT, Hans; JARAMILLO, Isabel Cristina; GACEL-AVILA, Jocelyne; KNIGHT, Jane. Educación Superior en América Latina: la dimensión internacional. Bogotá: Banco Mundial en coedición con Mayol Ediciones, 2005. p. 1-38.

KNIGHT, Jane. Internationalization remodeled: definition, approaches, and rationales. Journal of Studies in International Education, v. 8, n. 1, p. 5-32, Spring, 2004. DOI: https:// doi.org/10.1177/1028315303260832.

KNIGHT, Jane. Updating the definition of internationalization. International Higher Education, Boston, n. 33, Fall, p. 2-3, 2003. Disponível em: https://ejournals.bc.edu/ojs/ index.php/ihe/article/view/7391/6588. Acesso em: 10 nov. 2016.

KNIGHT, Jane. Internationalization of Higher Education. In: OECD. Quality and internationalisation in Higher Education. Paris: Programme on Institutional Management in Higher Education, 1999. p. 13-28.

KNIGHT, Jane. Internationalization of Higher Education: a conceptual framework. In: KNIGHT, Jane; DE WIT, Hans (Org.). Internationalization of Higher Education in Asia Pacific countries. Amsterdam: European Association for International Education, 1997. p. 5-19.

KNIGHT, Jane. Internationalization: elements \& checkpoints. Ottawa: Canadian Bureau for International Education, 1994.

KNIGHT, Jane; DE WIT, Hans (Ed.). Internationalization of Higher Education in Asia Pacific countries. Paris: Organization for Economic Cooperation \& Development, Case Studies and Stocktake; Camberra: DEETYA, 1997.

KNIGHT, Jane; DE WIT, Hans. Strategies for internationalization of Higher Education: historical and conceptual perspectives. In: DE WIT, Hans (Ed.). Strategies for internationalization of Higher Education. Amsterdam: EAIA, 1995. p. 5-32.

LIMA, Manolita Correia; CONTEL, Fábio Betioli. Períodos e motivações da internacionalização da Educação Superior brasileira. In: COLLOQUE DE L' IFBAE, 5., 18-19 maio 2009, Grenoble. Anais [...]. Grenoble, 2009. Disponível em: http://www.ifbae.com.br/congresso5/ pdfB0095.pdf. Acesso em: 14 jul. 2016.

LIPSETT, Anthea. Rise in university gender pay gap. The Guardian, 30 March, 2009. Disponível em: http://www.guardian.co.uk/education/2009/mar/30/rise-universitiesgender-pay-gap. Acesso em: 14 jul. 2016. 
MARMOLEJO, Francisco. Internationalization of Higher Education: the good, the bad, and the unexpected. Chronicle of Higher Education, Washington, DC, October 22, 2010. Disponível em: http://www.chronicle.com/blogs/worldwise/internationalization-ofhigher-education-the-good-the-bad-and-the-unexpected/27512. Acesso em: 14 jul. 2016.

MCGOWAN, Sue; POTTER, Lucy. The implications of the Chinese learner for the internationalization of the curriculum: an Australian perspective. Critical Perspectives on Accounting, v. 19, n. 2, p. 181-98, fev. 2008.

MESTENHAUSER, Josef A.; ELLINGBOE, Brenda J. Reforming the Higher Education curriculum: internationalizing the campus. Phoenix, AZ: American Council on education \& Oryx Press, 1998.

MIURA, Irene Kazumi. O processo de internacionalização da Universidade de São Paulo: um estudo em três áreas de conhecimento. 2006. Tese (Livre-Docência)-Faculdade de Economia, Administração e Contabilidade da Universidade de São Paulo, Ribeirão Preto, SP, 2006.

MUELLER, Cristina Verônica. O processo de internacionalização do Ensino Superior: um estudo de caso da Universidade Federal do Rio Grande do Sul. 2013. 178f. Dissertação (Mestrado em Relações Internacionais) - Instituto de Filosofia e Ciências Humanas, Universidade Federal do Rio Grande do Sul, Porto Alegre, 2013.

OLSON, David M.; DINERSTEIN, Eric; WIKRAMANAYAKE, Eric D.; BURGESS, Neil D.; POWELL, George V. N.; UNDERWOOD, Emma. C.; LOUCKS, Colby J. Terrestrial ecoregions of the world: a new map of life on earth: a new global map of terrestrial ecoregions provides an innovative tool for conserving biodiversity. BioScience, v. 51, n. 11, p. 933-8, 2001.

PICKERT, Sarah; TURLINGTON, Barbara. Internationalizing the undergraduate curriculum: a Handbook for Campus leaders. Washington, DC: American Council on Education, 1992.

POWELL, Colin. Statement for International Education Week. U.S. State Department, 2004. Disponível em: http://state.gov.iew/statements/powell.htm. Acesso em: 14 jul. 2016.

SCHOORINAN, Dilys. The pedagogical implications of diverse conceptualizations of internationalization: a U.S. based case study. Journal of Studies in International Education, v. 3, n. 2, p. 19-46, 1999. DOI: https://doi.org/10.1177/102831539900300203.

SODERQVIST, Minna. Internationalization and its management at Higher Education institutions: applying conceptual, content and discourse analysis. Helsinki, Finlândia: Helsinki School of Economics, 2002. 
VAN DER WENDE, Marijk. Internationalization of Higher Education in the OECD countries: challenges and opportunities for the coming decade. Journal of Studies in International Education, v. 11, n. 3-4, Fall-Winter, p. 274-89, 2007.

\section{Sobre o autor:}

José Camilo dos Santos Filho: Ph.D. em Educação pela University of Southern California. Mestre em Educação pela University of Southern California. Mestre em Administração Pública pela University of Southern California. Professor na Universidade Estadual de Campinas (UNICAMP). E-mail: jcamilosantos@gmail.com, Orcid: https://orcid.org/0000-0002-4183-0460

Recebido em 14 de outubro de 2019.

Aprovado em 16 de novembro de 2019. 